\title{
Using the Administration to Update and Evaluate Urban Planning for Cities
}

\author{
a \\ University of Technology, Department of Architecture Engineering

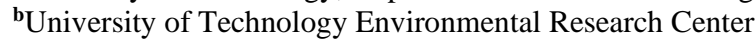 \\ 'University of Technology, Department of Architecture Engineering \\ dAssist \\ eAssista \\ fAssistan
}

Hadeel Mowafaaq Mahmood ${ }^{a}$, Amera K.Lafta ${ }^{b}$, and Ghada Ghalib abdulwahabm ${ }^{c}$

Article History: Received: 11 January 2021; Accepted: 27 February 2021; Published online: 5 April 2021

\begin{abstract}
The planning process takes place to face a number of challenges and obstacles that address and continue for a long time to form a plan that includes the fundamental changes in society and keep pace with population and urban growth, and planning and the formation of blueprints is a basis to meet the needs of society, but the passage of time to configure it to keep pace with growth and the speed of increasing population and technical growth, it requires research studies Faster to configure a re-planning of plans and studies as an alternative to re-planning and supporting them with follow-up and continuous evaluation processes that are among the basic components of management operations, which is the solution to reduce problems and shortcomings and support for planning processes as a current and long-term treatment The role of management is important to support the planning process in the presence of evaluation and follow-up to meet the requirements of the city and its expansion Urban development and development, and looking forward to the most prominent concepts and ways that decision-makers take with techniques and methods that make the city and the services provided to it in the best image that makes the city with urban development and urban management represented by the countries.
\end{abstract}

Keywords: urban planning, management, indicators.

\section{Introduction}

Management of urban architecture is not an easy process. This is due to the complexity of the formation of the urban environment, the many factors affecting its formation, the seriousness of the problems it faces, and at the same time a large number of administrative considerations, the complexity of relations among them, and the difficulty of the challenges they face. In this context, urban management turns into a societal responsibility in addition to being governmental.

Urban management represents the effective tool for the sustainability of urbanization, as it represents the forces controlling urbanization through planning and organizing processes in line with the capabilities and determinants that are linked with the concept of development management. It is also possible to bring about development by translating policies related to economic and social services and activities and transforming them into projects concerned with regional and local priority.

\section{Research problem.}

The approach used in urban planning loses its effectiveness and lack of integration due to the time taken and its requirements, which requires remedying the defect. and activating planning to achieve its required goals in a technical, sequential and follow-up manner with minimal time spent.

\section{Research goal.}

Activating basic management principles, monitoring and evaluation in the planning process, using urban monitoring method, and dealing with successive changes in a systematic, planned manner.

Research hypothesis.

Activating the role of management in monitoring and evaluation as they are planning elements to form an integrated planning process.

\section{Administration in cities:}

Management is one of the methods that are taken for the success of any work because it is the focus of its main work monitoring, follow-up, evaluation and implementation, and because cities and their urban requirements need management to develop this urbanization, as the concept of urban development management is defined as the means for organizing civil urbanization and it is a multiple and complex organization of concepts, processes, values and several laws That implement and translate goals and priorities into action plans that help improve the quality of the built environment in the city (1)

\section{Management foundations for urban development regeneration in cities.}

One of the basic matters that the administration cares about, including urban management, city urbanization management, and the continuous renewal of urban planning is the existence of concepts that depend on to find a perfect job in managing an optimal work and the formation of methods and methods that support the needs and requirements of the city's society in the finest form, namely: 
1_ Monitoring (2).

It is a concept concerned with collecting and analyzing data and finding results that serve the process of implementation, follow-up, and control, and mainly concerned with repeating the monitoring process to avoid a deviation from the development path, which is a process of achieving progress and success in implementing development interventions to achieve the results expected by the parties concerned for the planning process, to achieve their goals and the progress of business Planned, where there are several measurements and types of monitoring to keep pace with all cases of monitoring and follow-up of performance within the characteristics and objectives that are used in all measurements to serve all areas of life.

2_Follow-up (3).

It is a process devised to implement plans based on successive monitoring of plans, which includes measuring the extent of progress and level of performance, identifying the elements for early success and failure and is carried out continuously and works on implementing information from the use of indicators of projects and balanced planning of cities.

3- Evaluation (4).

It is a process that is complementary to the monitoring process that depends on the information resulting from monitoring and follow-up to analyze projects and programs and to create greater efficiency and effectiveness of activities and tasks. Available to change these projects depending on these studies.

4- Calendar (5)

It is concerned with the approaches, foundations and theoretical approaches to the process of comparison and evaluation between the concepts of follow-up, evaluation and monitoring and their connection to the objectives and their various degrees, which is a positive process to support the implementation of plans and projects, within the tasks of the evaluation process to correct deviations at the appropriate speed and implement these plans.

5_Urban monitoring (6).

It is an automated process for managing information and transforming it into indicators that support decisionmaking and help in preparing programs and policies for several projects and their budgets, and also helps sectors and several government agencies for local and non-local administration in the follow-up and monitoring process of cities and also contributes to strengthening the permanent tasks of monitoring urban conditions, as it works on Creating databases that automatically update "with work procedures and also publishing the measurement of the rate of achievement in the implementation of development using urban indicators. Urban monitoring is an efficient tool for monitoring supported by the spatial dimension of the monitored indicators, which helps statistical analysis and periodic comparison that helps in evaluating development policies in the city.

Urban planning

It aims to provide the best services and distribute optimal land uses, evaluate urban and rural life that meets the requirements of its communities, find engineering solutions to urban problems such as population inflation, slums, traffic crises, regulate movement between residents and services, etc., and multiple theories of regional and urban planning aim to regulate urban life, And the adoption of strategic management in it and represent all management means to provide a coherent method for setting a strategic agenda for the bodies accompanying the executive work in the administration, where its steps can be monitored and financed according to any new data, and urban planning is represented by being developed according to the requirements of cities by paying attention to economic and social problems and by finding theories and methods that implement methods that reduce This effect (7).

Urban planning is done depending on the levels of follow-up and evaluation processes, depending on the application of the following (8):

1- Projects, are the focus of activities in the short term.

2- Programs. It is a group of long-term activities.

3- Sector. It helps in a wide range of the sector in the long run.

4- The region. Looking forward and looking at the impact of interventions and policies at the regional level, and comparing regional action with the national level.

5- National. Knowing the long-term impacts of development programs.

\section{Management and use of indicators to support urban planning.}

Indicators are a basic measure that summarizes the required information for a specific topic, defining the problems that need to be solved and reduced, and depending on the priorities of urban development. (Such as region, gender, geographic, awareness, and several perceptions), updated to help define urban development priorities, and Table (1) clarifies indicators depending on the beneficiary and the land uses in the city (9)

Table No. (1) identifies the beneficiaries of the indicators for urban planning in cities / source - the researchers based on a number of readings in the formation of urban planning for a number of cities.

\begin{tabular}{|l|l|l|l|l|}
\hline Type of recipient & \multicolumn{3}{|l|}{ Uses and indications } & $\begin{array}{l}\text { Determine } \\
\text { the } \\
\text { Citizens }\end{array}$ \\
$\begin{array}{l}\text { Make decisions } \\
\text { about quality of } \\
\text { life }\end{array}$ & $\begin{array}{l}\text { Investment } \\
\text { decisions }\end{array}$ & $\begin{array}{l}\text { Election } \\
\text { Handbook }\end{array}$ \\
\hline
\end{tabular}




\begin{tabular}{|l|l|l|l|l|}
\hline & & & & $\begin{array}{l}\text { organizations } \\
\text { and activities }\end{array}$ \\
\hline $\begin{array}{l}\text { National } \\
\text { governments }\end{array}$ & $\begin{array}{l}\text { Measuring } \\
\text { government } \\
\text { effectiveness }\end{array}$ & $\begin{array}{l}\text { Follow up on } \\
\text { problems }\end{array}$ & $\begin{array}{l}\text { Stretching } \\
\text { Strategies }\end{array}$ & $\begin{array}{l}\text { Make } \\
\text { comparisons }\end{array}$ \\
\hline $\begin{array}{l}\text { City councilors, } \\
\text { managers and } \\
\text { councilors }\end{array}$ & Follow up policies & $\begin{array}{l}\text { Follow up } \\
\text { performance }\end{array}$ & $\begin{array}{l}\text { Measure usage for } \\
\text { money }\end{array}$ & $\begin{array}{l}\text { Measuring } \\
\text { investment } \\
\text { decisions }\end{array}$ \\
\hline private sector & $\begin{array}{l}\text { Production and } \\
\text { shopping }\end{array}$ & $\begin{array}{l}\text { Information for } \\
\text { investment } \\
\text { decision- } \\
\text { making }\end{array}$ & $\begin{array}{l}\text { Loans and } \\
\text { borrowings }\end{array}$ & Calendar \\
\hline $\begin{array}{l}\text { NGOs and local } \\
\text { community } \\
\text { organizations }\end{array}$ & Funding request & $\begin{array}{l}\text { Follow up on } \\
\text { government } \\
\text { performance }\end{array}$ & Research & \\
\hline $\begin{array}{l}\text { International } \\
\text { agencies }\end{array}$ & $\begin{array}{l}\text { Determine the } \\
\text { success of its } \\
\text { programs }\end{array}$ & $\begin{array}{l}\text { Identify areas } \\
\text { most in need of } \\
\text { help }\end{array}$ & & \\
\hline
\end{tabular}

International experiences are studied to identify the method taken using an administrative method and to evaluate, follow up, and connectivity between the new cities and their neighborhoods, and to benefit from them in Iraqi cities.

Los Angeles (10)

It is characterized by urbanization and urban distribution. Los Angeles was known as one of the major urban cities concerned with urban planning and optimal distribution of land uses. It was distinguished by an urban administration known to distribute commercial, economic and service areas, sign buildings as needed and deliver services to them, and that most of its urban centers after working hours are known as the calm of cities and flourish in movement In the evening, "with the presence of restaurants and tourist sites to serve the city's population, as most of the workers reside outside the city (the suburbs), which gradually transformed" into cities because of the urban and population growth and the strategy that paid attention to those sites and the interest in nature and the economic factor being the main solution in establishing economic stability in the suburbs, and the city was taken Management policy and strategic planning and the participation of the partnership method for the advancement of reality for urban areas by setting the future vision of economic development, and that civil society has an effective role especially in the "suburbs" and often plays a major role in strategic urban planning, relying on an administrative method and monitoring and evaluation from time to time, to maintain design and implementation Prepared planning, avoiding problems in The urban environment of the city or its reduction through monitoring and monitoring, and this is what we see in the reality of current cities in the United States of America.
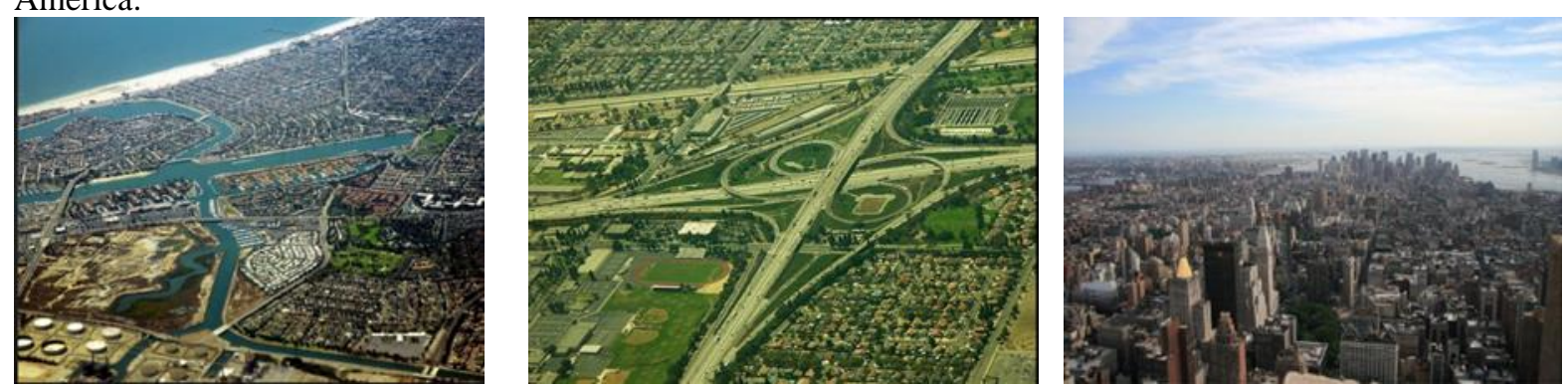

Pictures showing the urban landscape, the distribution of land uses, and the types of land uses distributed in the city / source Internet.

Makkah al-Mukarramah (Makkah Hills) planning experiment (11)

Saudi Arabia has taken an approach to its cities that sought to change reality into a better one by focusing on strategic urban planning in an administrative manner and with the help of global and Arab expertise. The elements that characterize the city, including the constant and escalating demand for real estate and a good return on investment, and the demand is concentrated in the Holy Capital now near the Holy Mosque in Mecca to serve the visitors and meet the needs of the city and its community, and that the city of Makkah includes several cities, including a site planned for the Makkah Hills project on the road The expressway between the city of Jeddah and Makkah Al-Mukarramah, and the following pictures show the location of the city and its distance from the Holy Mosque and its link with the city and the extent of its expansion. 

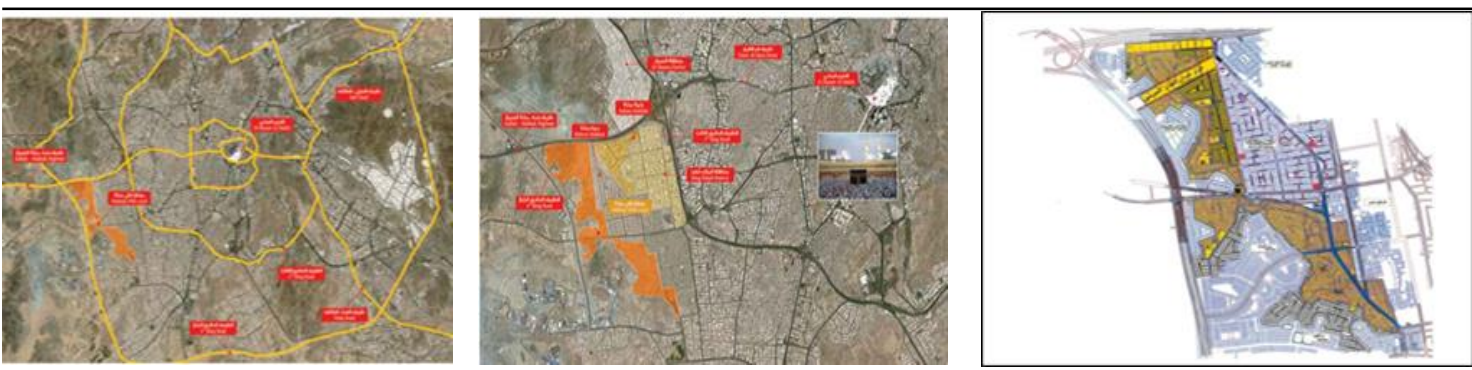

The project site shows Makkah Hills and the distribution of the land uses signed for a site and is planned with a clear distribution and administrative strategy for optimal urban planning / Source Book F7, pg. 235

The site is about 5.5 kilometers from the Grand Mosque, and the project consists of a group of commercial and residential facilities for multiple uses, on an area of 1.918 .639 square meters located between the third and fourth ring road and on the Makkah-Jeddah highway. With the city, by making a balance in the distribution of services upon urban expansion and growth, and by using an administrative method that controls the follow-up, evaluation, and implementation of several tasks based on the study and determination of a strategy that meets the requirements of the city.

Bismayah city experience (13).

The city of Baghdad is one of the big cities in which it has recently been known for urban expansion and unplanned population growth, so it required the expansion of a plan belonging to the capital and the formation of a city in Bismayah that was known for its ideal designs and planning. In terms of construction, provision of services, and the use of a balanced and thoughtful administrative style inside the city, but outside the city, there is a visual distortion and lack of keeping up with the visual scene inside and outside the city and the interconnectedness of transportation and the distribution of buildings with the interconnectedness of the scene, and it requires an administrative style by the local administration, paying attention to neighborhoods, providing services, raising the difference or reducing it, and the difference in level Life and the provision of services within the city in Samaya and its neighborhoods, and this problem suffered by the residents of the city or its neighborhoods and the class difference and in the provision of services or their lack thereof, the spread of slums and the visual distortion of most neighborhoods adjacent to Bismayah, the lack of management by the local administration and the lack of follow-up and evaluation, which makes the difference and difference in the urban scene of the city and its neighborhoods.

Through the questionnaire and looking forward to the field visit, it was revealed the existence of service provision and interconnection with a distinct urban scene of the city and its internal streets and its somewhat sufficiency, but weakness and difference in the urban landscape that characterizes the neighboring neighborhoods, with visual and environmental distortion, tangible environmental differences and the increase in urban problems, including transportation due to roads, pollution and other Urban problems, and this is what was evident during the field visit, through which a tangible commercial and industrial spread and uninvested lands adjacent to the city of Bismayah and made it an isolated city satisfying services within the city and isolated from its neighborhoods, and this is what was known through the questionnaire For a number of respondents by 50 forms showing the reaction of the city's residents, and the attached pictures show the discontent of the city's community And the demand to provide integrated services within the city and its interconnectedness with its neighborhoods, to highlight the local administration service and the interconnectedness of tasks, and to activate the role of administration and its components of evaluation and follow-up to reduce urban problems as much as possible The deficiencies in the performance of the local administration and the provision of services appeared, and the difference between inside and around the city.
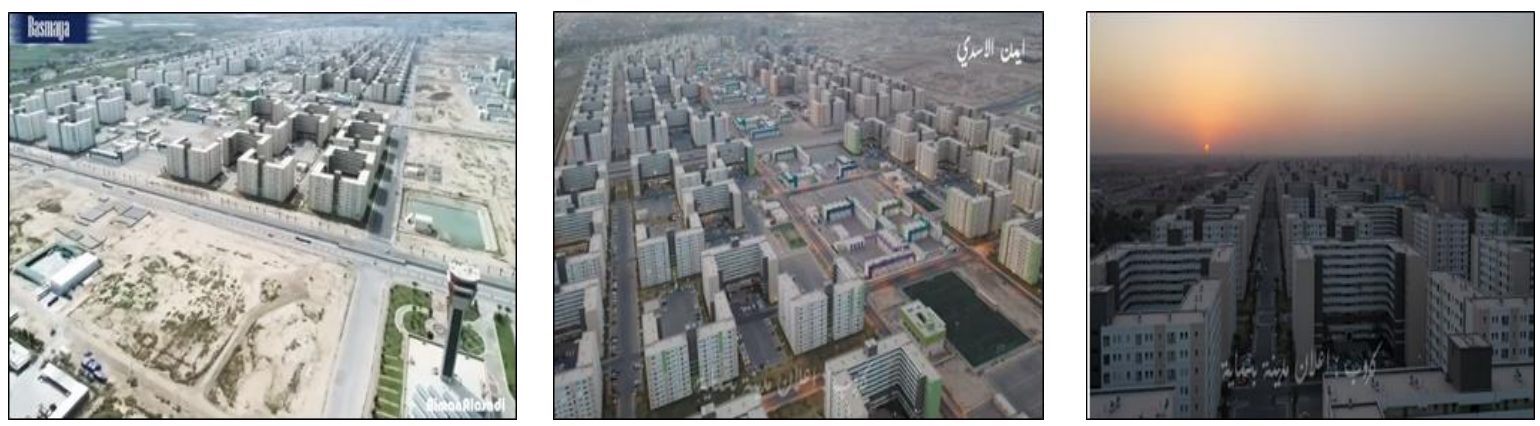

Pictures showing the city of Bismayah and the distribution of buildings with a balanced urban landscape / source www.youtube.com/watch?v=godydUQaez4 


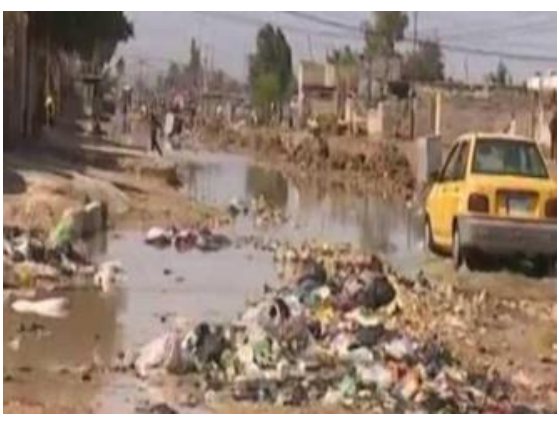

A picture showing the scene for the distribution of buildings and services provided to neighborhoods near the city of Basmajah / Source: Researcher field visit
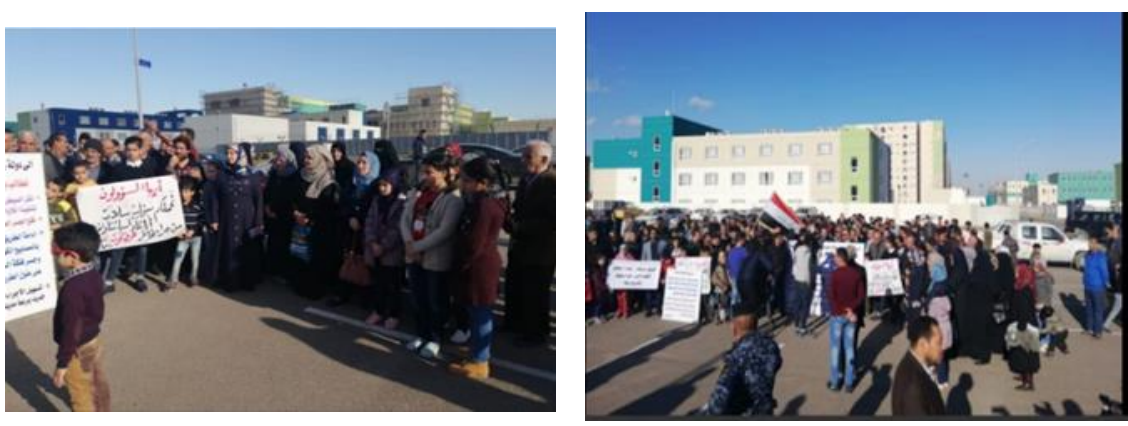

Pictures showing the difference in providing services and the residents' dissatisfaction with the roads surrounding the city / the Internet source

\section{Conclusion}

1- Urban planning provides a somewhat luxurious life or meets the needs of its community to form an urban city while ensuring a future for a city compatible with the changing needs of them, and taking urban planning in the neighborhoods of cities and improving their conditions by re-planning them, due to a fundamental result of radical changes in the composition Cities, crumbling infrastructures, lack of maintenance, lack of services, neglect, and failure to meet the need for population growth, which generates economic and social problems that require a change in the strategy of city management.

2 - Management and strategic plans pursued by countries, including Makkah and Los Angeles, are to rely on decentralization and use a balanced and participatory decision-administration approach, to achieve the vision that the state seeks through investment and the development of participation by decision-makers with the beneficiaries, especially in the hills of Makkah and Los Angeles. After taking care of it and re-planning it.

3- Some experiences are being studied for multiple countries that used modern technologies and modern methods of urban planning to be relied upon and to identify the approach taken to reach the most appropriate methods for solving existing problems in innovative ways that are compatible with the dynamics of cities that keep pace with the different changes.

4- The city of Basmajah is one of the ideal cities for design, planning, and implementation, but the weak administrative coherence of the local government and government institutions has resulted in a deficit and weakness in the administrative tasks, which caused a deficit of services outside the city and a lack of interconnection between it and its neighborhoods, which gave rise to some problems due to dissociation and isolation in the provision of services.

5- Urbanization does not enjoy an administrative structure commensurate with the requirements of the citizens who inhabit it, and its administration is dispersed between the various state agencies that do not operate in one framework or a common organization.

\section{Recommendations}

1. Strategic urban planning requires its introduction, as it means a far-reaching study, declaration of intentions, and determination of what the decision-making bodies desire with the help of the competent authorities in the strategic planning department.

2. Urban planning is the art of those who formulate and teach those who search for its development and beautiful reality that is translated by follow-up during implementation and application of management tasks to achieve it, strategically because it is based on a future vision, monitoring the future, providing services and rationalizing consumption in the long term in the urban landscape, and the interconnectedness of services requires the implementation of strategic management Urban Planning works to implement urban plans to achieve cities that meet their needs with strategic management that works to balance resources and results as much as possible with the reality between cities and their neighborhoods.

3. Creating cities that have urban characteristics that give development and sustainability at the same time. These are the goals of planning, and it requires a strategy followed by an administration that works on urban planning in partnership and activating decentralization, but with government oversight, laws and legislation are applied that achieve cities that are growing and with strategy management that works on the sustainability and development of cities.

4. Developing the planning process and the development vision based on a database, evaluation, and followup of the planning outputs that are periodically updated for these data. 


\section{References.}

1. Hisham Abdullah Al-Ghariri, Administration, Analytical Study, Al-Falah Library for Publishing and Distribution, Kuwait, 2010, pp. 91-98.

2. Regional Development Administration (Medina Municipality), Ministry of Municipal and Rural Affairs, Kingdom of Saudi Arabia, experience of establishing a local urban observatory for Greater Madinah, a documentary study -2006 .

3. Al-Wakeel, Shafak Mahmoud, Principles of Urban Planning - Foundations of its Applications, Part - One, Cairo, 2008.

4. Hazem Al-Quwaidi, "Urban Challenges at the National Level and the Authority's Vision for the Development of the Urban Planning and Development System", Ministry of Housing, Utilities and Urban Communities, General Authority for Urban Planning, Cairo - Egypt, January 7, 2008.

5. Salah Al-Din Mahmoud Arman, Good Urban Management between Urban Planning and Local Governance i.e., Khartoum State, 1999.

6. Mitchell. Assessing the sustainability of development plans for outer urban areas: some key issues for the SOLUTION trogect presentation to the 2nd national SOLUTION conference, university college London desember2005, pp38.

7. Schnur, Olaf, Exploring Social Capital as an Urban Neighborhood Resource: Empirical Findings and Strategic Conclusions of a Case Study in Berlin-Moabit. Tijdschrift voor Economics en Sociale Geografie96(5):488-505 (2005).

8. El-Faramawy, Ali, Strategic Urban Planning in Egypt. UNEP and UN-HABITAT Regional Office for Africa and Arab States ,Urban Environment, January (2007).

9. Srinidhi S., Raghavan, N., Srinivasa R. and Srinivasan, R., Modeling Urban TrafficPlanningthroughStrategicDecisions-Acase from Bangalore, India. Department of Management Studies, Indian Institute of Science (2004).

10. Historic Cities \& Sacred sites / Cultural Roots For urban Future -World Bank , Ism-Serage - Eph Sh.J.Martin B,2012.

11. Abdullah bin Omar Bahussain Bafail, Strategic Urban Planning and Strategic Management of Cities, King Bin Abdulaziz University Press, 4th Edition, 2014.

12. Li, Haiying and Dong, Lan, Research on Urban Core Competitive Competence (CCC) under the Background of Knowledge Economy. USA-China Business Review 7 (2007).

13. http://www.bismayah.org/pages/02unitplan/traditional_type.asp

14. https://www.democraticac.de/?p=65477

15. Questionnaire form

16. Hi ..

17. Please questionnaires for the purposes of scientific research and evaluation of services for the city of Bismayah, which describes the sustainability and the ecological characteristics of the city, which works to reduce the problems that the city suffers from and to maintain a balanced urban environment.

18. 1_ The number of family members is 4 members ( ) 6 members ( ) 8 members ( )

19. 2- Is the occupying complex of the city served by infrastructure services? Yes ( ) No ( )

20. 3- The privacy of the city of Bismayah has helped the safety and security of the community that preoccupies it Yes ( ) No ( )

21. 4- Is the city interconnected with the demolitions of neighboring neighborhoods? Yes () No ()

22. 5- The administrative style followed in the city causes it to be preserved. Yes () No ()

23. 6- Does the local administration achieve interconnection between the services provided to the city and its neighborhoods? Yes () No ()

24. 7-The city and its requirements meet the requirements of its society in all or some of them. Yes () No ()

25. 8- Planning and implementation of the basics required by cities are available in Basmajah city Yes () No ()

26. 9-Is there an evaluation and follow-up of the services provided inside Basmajah? Yes () No ()

27. 10- Is there an evaluation and follow-up of the services provided outside Bismayah and the surrounding neighborhoods?

28. 11- Is there an optimal distribution of land uses in your view that achieves a balance for urban life that meets the requirements of its communities? Yes () No ().

29. 12- Is there an effect of local administration inside and outside the city? Yes () No ()

30. 13- There is an update for the urban planning of the city of Baghdad and with follow-up plans, whether or not, in your opinion, yes () no (). 